\title{
DOES MOLECULAR MODELING EXPLAIN THE ORIGIN OF THE MICROTUBULE-CURLING EFFECT IN CANCER CELLS INDUCED BY SOME PODOPYLLOTOXIN ESTERS?
}

\author{
N. Zefirov ${ }^{1,2}$, A. Glaßl ${ }^{3}$, A. Borovyk1, E. Radchenko ${ }^{1,2}$, E. Milaeva ${ }^{1,2}$, \\ S. Kuznetsov ${ }^{3}$ and O. Zefirova ${ }^{1,2}$ \\ ${ }^{1}$ Department of Chemistry, M.V. Lomonosov Moscow State University, \\ 119992, Russia, Moscow, Leninskie gory, 1/3. \\ ${ }^{2}$ Institute of Physiologically Active Compounds, Russian Academy of Sciences, \\ 142432, Russia, Chernogolovka, Severny pr., 1. \\ ${ }^{3}$ Institute of Biological Sciences, University of Rostock, \\ D-18059, Rostock, Germany, Albert-Einstein-Str., 3.
}

DOI: 10.19163/MedChemRussia2021-2021-175

E-mail: kolaz92@gmail.com

Natural lignan podophyllotoxin (PF, 1) possesses pronounced anticancer activity due to its ability to inhibit polymerization of $\alpha, \beta$-tubulin to microtubules (MTs) leading to a disruption of cell division. PF is not applied in chemotherapy because of its high general toxicity, so numerous its analogues were synthesized in a search of more safe drugs. The majority of these analogues were obtained by modification at $\mathrm{C}^{4}$ of PF structure. In the course of these works several bridged esters were obtained and tested on cancer cell lines [1-4]. Some of these esters altered the dynamics of microtubule cytoskeleton in unusual manner by stimulating the formation of involuted structures defined as «curled MTs» (see the picture). As though active podophylloxin derivatives generally cause the MTs depolymerization only, we performed computer molecular docking and molecular dynamics study of expanded series of complexes $C^{4}$-PF esters - tubulin with the aim to explain the origin of MTs curling effect.
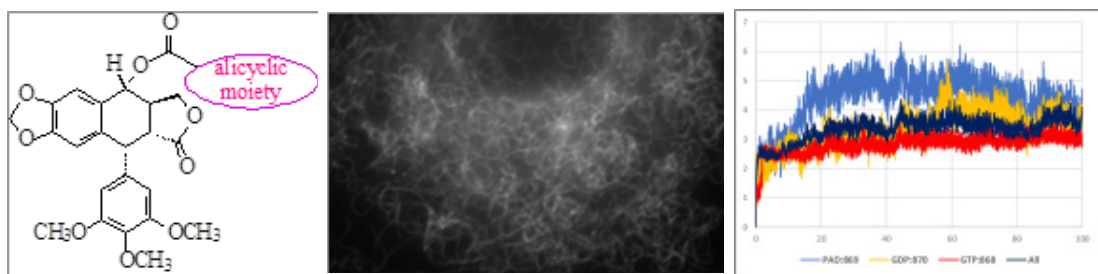

The study allowed proposing two different hypotheses explaining the MTs «curling» action and its relation to cytotoxicity to cancer cells.

The work was partially supported by Russian Science Foundation (project 19-13-00084).

\section{References}

[1] N. A. Zefirov, A. Kruth, B. Wobith et al, Mendeleev Commun., 2018, 28, 47.

[2] N. A. Zefirov, Yu. A. Evteeva, B. Wobith, S. A. Kuznetsov, O. N. Zefirova, Struct. Chem., 2019, $30,465$.

[3] J. L. López-Pérez, E. del Olmo, B. de Pascual-Teresa et al, Bioorg. Med. Chem., 2004, 14, 1283.

[4] N. A. Zefirov, E. A. Lavrushkina et al, Biomedicinskaia Chimia (in Russ.), 2019, 65, 86. 